\title{
Research on the Quality Audit and Self- assessment for Integrated Quality Management
}

\author{
Li sheng \\ International School \\ Wuhan University of Science and Technology \\ Wuhan, China \\ e-mail: lisheng@wust.edu.cn
}

\begin{abstract}
This paper establishes the practices of quality management and its progression that underlies the concepts of business excellence. It is substantiated by the taxonomy of quality assessment models, where self-assessment has to be supported by a structured scoring system which needs to be precise in evaluating the organisations' management practices, and identifying opportunities for improvement. This paper concludes by recommending a hybrid approach for selfassessment. The approach shall give an objective and consistent evaluation of the organisation maturity in managing performance and improvements.
\end{abstract}

Keywords-audit; Self-assessment; quality;

\section{INTRODUCTION}

There is very little doubt that quality audit and selfassessment are self-administered processes which complement quality management and improvement. The underlying precept is that improvement cannot be recognised unless the quality management practices and performance are evaluated, wherein the audit and self-assessment are meant to support and facilitate improvement. However, in the survey conducted Wiele et al state that there is still some confusion between the audit undertaken as part of the ISO 9000 certification requirements and self-assessment based on business excellence criteria. According to Karapetrovic and Willborn a quality audit measures the effectiveness and achieved improvement of an organisation's quality system against the requirements of the ISO 9000 standards. In contrary, self-assessment evaluates the effectiveness and efficiency of the organisations and the maturity of the quality management system [ISO 9004 Guidelines].

\section{REPORTED PERSPECTIVES FOR QUALITY AUDIT}

As espoused by Zink and Schmidt, the important goals of self-assessment are:

- to identify the state-of-the-art of the quality endeavours within the organisation,

- to create an organisation-wide strategy and approach in addressing improvements, and

- to facilitate changes in the business environment.

Conti [1997b] also maintains quality audit checks compliance with pre-specified rules and performance standards in well-regulated areas of the company. It is concerned with tangible characteristics which can be assessed with a fair degree of objectivity. According to Conti [1997a], the situation is different with self-assessment which requires objectivity and brings into play many intangible characteristics that are difficult to measure or assess.

A major difference between quality audit and selfassessment is the intent in implementing the approaches [Porter and Tanner, 1996; Karapetrovic and Willborn 2001a]. Second and third parties quality audits are externally driven and most often from demanding customers to have the organisations certified in ensuring a standard level for maintaining quality products and processes. Wiele et al [2000] also comment that once the organisation is certified, it becomes management responsibility to keep the quality system working, and improvements are carried through corrective and preventive actions. For self-assessment it has been an internal decision to enhance the quality management of processes toward world-class performance. It is therefore the starting point for a regular strategic or operative planning process within the company which ensures a continual quality improvement [Caffyn, 1999; Conti, 1993]. Thus ISO 9000 quality standards and business excellence criteria, as auditing and assessment systems, have different goals and perspectives [Zink et al, 1994; Porter and Tanner, 1996; Wiele, 1998], such as:

- $\quad$ extent to which the audit is an independent audit,

- business excellence as reference versus internal policy and plans as reference,

- identification of strengths and weaknesses versus non-conformities, and

- $\quad$ planned improvements and dynamic change versus keeping things on the same level.

Where quality audit is concerned, a large spectrum of views on this issue emerges [Barthelemy and Zairi, 1994, Bredrup, 1999; Curkovic and Pagell, 1999; Curkovic and Handfield, 1996]; however Beeler [1999] claims that audit cannot drive continual improvement. If conducted properly they can contribute to the improvement of the organisation's processes and products. Peter [1998] reckons dynamic and proactive auditing can induce improvement, while static auditing ensures compliance with the necessary minimum standards. Karapetrovic and Willborn [2001a] present several conditions for a successful audit use in improvement efforts, including the constant change of excellence models and interdependence of audits. 
In any continual improvement effort, the contribution of ISO 9000 quality audit is to provide the foundation to enhance the discipline for business excellence. As a quality assessor and auditor I consider both the audit and selfassessment are complimentary in the improvement initiatives. However, there is a wide gap between the requirements of ISO series and the level of quality management maturity demanded by the business excellence models. Dales [1999] identifies six levels of quality awards adoption which can be referenced to ISO certification requirements:

(1) Uncommitted;

(2) Drifters,

(3) Tool pushers,

(4) Improvements,

(5) Award winners, and

(6) World class.

Organisations that are certified to ISO 9000 requirements and who have made little or no advancement in their quality management effort will tend to be at levels (1), (2), or (3), whereas those using the self-assessment will at levels (4), (5) or (6).

Russel and Regal [1996] had argued that the emphases on quality audit are corrective and preventive actions, which link non-compliances with follow-up actions, while selfassessments have the ability to incorporate the outcomes directly into strategic planning process. However, quality audit also provides many advantages, including their objectivity, independence of evaluation and recommendations, as well a solid assurance of the existence and operations of a quality system, as described in the relevant standards. These are reiterated by Uzumeri and Tabor [1997], which according to the compliance nature of the audit criteria and had been developed to uphold the principle of independence, objectivity and a documented search for evidence. From my understanding, this is in contrast to the holistic nature of quality award where linkages between the processes have to be established, wherein self-assessment is to evaluate the inter-dependencies and their alignment to the organisation's goals and vision. By evaluating the different level of performance, Dale [1999], and Karapetrovic and Willborn [2001b] had contended that ISO 9000:1994 standards and NQA models really reflect different levels of maturity in business excellence. Karapetrovic and Willborn [2001b] advocate that corresponding evaluation methodologies should be developed to measure differing levels of such excellence, with quality audit and self-assessment equipped for evaluation of lower and higher levels, respectively. Wiele et al [1995] and Conti [1997] had also expressed the differences between the ISO 9000:1994 series related audit and self-assessment based on the much broader definition of quality management. As had concluded by Porter [1996], when applied effectively the audit process is one of most powerful techniques, for use in both an "award" situation and a self-assessment situation. I also accept their arguments, however in my research I consider the perspectives between quality audit and self-assessment is less diverse and contentious, if I am able to establish the objectivity of selfassessment and supported by its evidence. The main purpose is to provide a valuable insight into the gaps that help to determine core strengths and weaknesses, and prioritise improvement opportunities based on the organisation's goals and objectives. In my view, a hybrid approach in selfassessment needs to be developed to evaluate the assurance requirements that reinforce the management system for business excellence. The enhancement of self-assessment ensures organisations that are certified to ISO 9000 Requirements meet the international quality standard and advance their quality management effort for business excellence recognition.

\section{PROBLEMS OF SELF-ASSESSMENT}

In acquiescence with Antitila [1994], MacKerron and McGlynn [2000], self-assessment has to be carried out with reference to a model, where its appropriateness is crucial to ensure the successful implementation and execution of strategy that drives organisation towards better performance. Since all NQA models are non-prescriptive, organisations are expected to understand their performance gaps, and through self-assessment facilitate changes as they develop and improve. However, the process in evaluating the score is complicated, with anomalies for subjectivity and computational variances. As a SQA assessor it has brought to my attention that SQA scoring system are also subjected to the same weaknesses, where assessment of the approach has to consider the deployment in getting a balance score between deployment and approach. This is usually a difficult task, as assessors have to determine the extent of deployment for each approach. Nevertheless, there is always a propensity in assessment by considering the factors in evaluating the approaches, assuming the deployment is complete.

In the pursuit for business excellence, self-assessment models do provide organisations with guidelines for assessing their progress and how they can be evaluated in providing the feedback for improvements. The aim is to have a scoring system that provides systematic and precise evaluation against the criteria of the selected model, identify and prioritise areas for improvement and to guide organisations in their path to excellence. The question is: Are these self-assessment models achieving this intent? In this aspect, I think that there is still a long way to go, my arguments are:

- The approach to assessment depends on the experience and competency of the organisations in carrying out the process. Unless the assessors are trained in the method of scoring and calibrated to the business excellence criteria, there will be variations in the self-assessment results.

- The final score for business excellence is always the outcome of the personal judgements of a particular assessment team, and cannot be easily replicated or generalised. This is an important limitation, particularly when the model is used as a benchmarking tool. 
- High score against the criteria is not a necessary or sufficient condition for success, especially the financial performances, which is only one of the organisations' results. Very often organisations have perceived the scoring to excellence in financial and operational results, with little considerations for other perspectives e.g. people, customer, etc. The focus is on the short-term objectives with little emphasis on long-term goals. It is important to remember that many internal and external factors influence the financial results and meeting the excellence criteria enhances management's control over these factors and makes the organisation more robust in dealing with changes.

- Assessment for business excellence is to review the management practices of organisation by evaluating against the criteria, with objective scoring that identifies the areas for improvement. However, focus on the criteria is difficult to establish an overview of the organisation's performance, particularly when it is an external assessment. It is ambiguous how improvements can be prioritised to achieve the desired results, when the external assessments are based on the organisation's reports and site visits. Also, the effect of any change on one particular criterion on the other criteria and overall performance is difficult to envisage.

The above limitations and the methods of assessment have reduced the objective effectiveness of the intent, very often it can mislead organisations in thinking that there is no "serious" problems since their assessment score is high. Nevertheless, the process is still an important tool for sharing experience and good practices among the organisations that are committed to improvement, which also explain the increasing number of organisations are using self-assessment model as a basis for world-class performance. I cannot refute these facts and the purpose is to improve the instrument of self-assessment and a system that evaluates the results for factual decision making, taking into consideration the inherent problems may still remains.

\section{CHARACTERISTICS AND ISSUES}

As a process, I regard quality audit aims at the maintenance of quality management system by identifying nonconformities and ensuring corrective actions are implemented. It have been criticised by Curkovic and Pagell [1999] for its failure to assess the extent to which a company's planning processes and quality requirements are integrated into its business planning. In contrasts, selfassessment is carried out to seek improvement opportunities by comparing current and best practices through results of the internal performance and external users of the organisations. The processes and quality systems are analysed and evaluated from the business contexts, wherein improvements are identified and prioritised in relation to the strategy, market competitiveness and business goals. While self-assessment is proactive and seeks to identify improvement opportunities, quality audit is reactive by confining to the determination of non-compliances and to clarify issues that are pertinent to the maintenance of the quality management system. The audit process is structured; and for the purpose of certification it has to be carried out by external bodies that are empowered to perform the third party quality audit.

In my opinion, there is very little doubt that quality audit and self-assessment are meant to support and facilitate improvement within its own contexts. In retrospective it is necessary to question their applicability in enabling performance improvement or limited to the maintenance of quality management system:

- Quality audit is to determine the compliance or conformity with the quality management standards, representing the audit outcomes. This helps to reinforce the quality assurance of the products and processes, where any improvement is discrete and step-wise through corrective or preventive actions. Self-assessment will only be significant if the results and performance measures are indicative for business excellence. The process aims at performance improvement by identifying strengths, weaknesses and opportunities for improvement.

- Audit is concerned with the objective evidence and records that are prescribed in the quality manual. In contrast with audit's objectivity, selfassessment is highly diagnostic with attempts to determine the range between the target and defined baseline. This also increases the range of variation, where subjectivity of evaluations has to be rationalised and agreed by the assessors.

- The scope of application represents another major difference. Quality audit is used for functionspecific assessments, and is planned for each function in an organisation. Thus, it remains function and process-focused. In contrast, selfassessment covers all the aspects of business processes, and involves cross-functional linkages that are aligned with the goals and objectives, where experience and knowledge contributes to the accuracy of findings and consistency in the evaluation.

- In the method of evaluation, quality audit involves basically objective verification of existing of quality system elements. Selfassessment is a number of scoring levels that categorised the maturity of the organisation. This is further accentuated by the weighted values for each criterion, emphasising their importance for business excellence. 
- $\quad$ The reliability and completeness in the gathering of data and information illustrates a possible downside for self-assessments, where subjectivity is always a concern in any assessment. Quality auditing involves gathering of evidence by observations, interviews, sampling and product tracking, with emphasis on the materiality and objectivity of information, to the point where audit evidence must be verified before it is actually used for evaluation against standards.

Since performance improvements in organisations are usually not subject of objective and structured external reviews, the weakness of self-assessment is that identified areas for improvement are left to the responsibility of the management. In contrast to the obligatory requirements of ISO 9001, improvements for business excellence are highly dependent on the commitment of top management and involvement of the people within the organisation. Unless there is a follow-up in the recommendation with an action plan, effectiveness of self-assessment can be nullified and the desired benefits not attained. Despite the weaknesses, self-assessment provides the instrument for comparison, evaluation and improvement. In my opinion self-assessment instrument has to be objective, with guidance for incremental performance improvement, and the process has to be rigorous and systematic by incorporating the acceded strength of quality audit.

The shortcoming of quality audits in ensuring continual improvement may lead to the belief that they should be dropped and replaced with self-assessment. Such a belief would ignore the advantages quality audit provides; including their objectivity, independence of evaluation and recommendations, as well as a robust process of evaluating the existence and operations of quality management system. Thus a hybrid approach for self-assessment can overcome the individual weaknesses. The aim is to improve the accuracy, precision and consistency in evaluating the criteria and enhance self-assessment as a process that achieves the desired benefits in using the business excellence models. It also assures that areas that are certified to ISO 9001 are complied as stipulated in the standards' requirements. The purpose is to ensure that organisations will consistently seek to improve themselves and that compliance to international standards for quality are not compromise in their journey for business excellence.

\section{CONCLUSION}

Generally, the criteria for business excellence are quite similar; it is the management approach in incorporating strategy and quality that differentiates the management maturity of organisations. The focus should not be on the criteria, but on the management practices of quality contents for business excellence. With this arrangement, selfassessment can give an objective evaluation of the organisation. The other concern which needs to be addressed is the method of evaluation. Since scoring is not an exact science and there are variations in the assessment methods, the rigorous use of scoring system and training can help to minimise these variations. The scoring system is used throughout the assessment process and requires constant calibration in ensuring consistency, which in my opinion is not an effective way of evaluation. This can be improved by using MAG which identifies the incremental step of maturity for each self-assessed items. In this thesis my approach is to use MAG as the instrument for assessing the Maturity Level of Quality Contents, which serves the amalgamation of quality auditing and self-assessment. Results of self-assessment items can be evaluated and reviewed at different management levels. These are consolidated to give an overview of the organisation's effectiveness and converted into SQA score for business excellence. The intention is to provide an objective and discrete method of self-assessment that can assist organisations to determine, evaluate and prioritise improvement, with the versatility in adapting to the changes that occurs within the business environment.

\section{ACKNOWLEDGMENT}

The author would like to thank Puah Kok Yong for his support and providing invaluable materials and advice.

\section{REFERENCES}

[1] Blazey, M.L [2000], Insights to Performance Excellence,2000, ASQ Quality press.Milwaukee,Wisconsin.

[2] Ahmed, P.K. [2000], "Sustaining the Corporation: 4 Cs for Motivation and Transformation in the Business Process Management Paradigm", Business Process Management Journal, Vol.6, No.1, pp.69.

[3] Bohoris, G.A . [1995], "A Comparative Assessment of Some Major Quality Awards/',International Journal of Quality and Reliability Management, Vol.12 No.9, pp.30-34.

[4] Cabinet Office, [1996], Measuring Quality Improvements, Toolkit for Effective Measurement, Published by TQM International Ltd. For Development Division, Cabinet Office, Crown Copyright Reserved, ISBN 0711503095.

[5] Productivity and Standards Board, Singapore . [2000], Singapore Quality for Business Excellence, Award Criteria Framework.

[6] Armistead, C., Machin, S. and Pritchard, J.P. [1997], "Approaches to Business Process Management", Conference Papers from the 4th International Conference of the European Operations Management /lssoc;'a lion, IESE, Barcelona, Spain.

[7] Soon, F. [2002]; "Journey Towards Business Excellence", Singapore Quality Institute Symposium, 2002,Singapore Quality Institute. 